\title{
Effects of temperature and the presence of benthic predators on the vertical distribution of the ctenophore Pleurobrachia pileus
}

Received: 28 August 2003/ Accepted: 3 March 2004/Published online: 25 March 2004

(C) Springer-Verlag 2004

\begin{abstract}
This study details the investigations of the effect of temperature and the presence of predators on the vertical distribution of the ctenophore Pleurobrachia pileus. Previous studies had suggested that $P$. pileus moves to the sediment when exposed to colder temperatures as an energy saving strategy. Although we did observe an effect of temperature on the movement of the ciliate combs, the effect of temperature on the average depth of animals in the water column was not significant, but a significant interaction was found between temperature and exposure time. In the presence of benthic predators or of water previously inhabited by these predators $P$. pileus changed its vertical distribution significantly, and moved away from the sediment, thus reducing the risk of being predated. We conclude that $P$. pileus can sense the presence of its predators, and changes its behaviour accordingly.
\end{abstract}

\section{Introduction}

The ctenophore Pleurobrachia pileus is a very abundant invertebrate in many temperate coastal seas. It can be an important predator on other zooplankters (Kuipers

Communicated by O. Kinne, Oldendorf/Luhe

M. Esser · M. Boersma ( $\bowtie)$

Biologische Anstalt Helgoland,

Alfred-Wegener-Institut für Polar- und Meeresforschung,

Postfach 180, 27483 Helgoland, Germany

E-mail: mboersma@awi-bremerhaven.de

Tel.: + 49-4725-819350

W. Greve

Forschungsinstitut Senckenberg, Notkestrasse 31, 22607 Hamburg, Germany

Present address: M. Esser

Institut für Zoologie, Allgemeine Ökologie und Limnologie, Universität zu Köln, Weyertal 119, 50923 Cologne, Germany et al. 1990), and is itself the most important prey organism for another ctenophore, Beroe gracilis (Greve 1971). Although populations of $P$. pileus and of other Pleurobrachia species can reach high densities in certain periods of the year $\left(>10\right.$ ind. $\left.\mathrm{m}^{-3}\right)$, with the corresponding predation rates of up to 300 copepods $\mathrm{m}^{-3}$ day $^{-1}$ (Greve 1971), information available on behaviour, population dynamics and ecosystem impact is still scarce, and existing reports often contain conflicting information. In recent years, however, the interest in ctenophores has increased considerably, as a result of the invasion of several species into the Black Sea and the resulting consequences for the fish populations (Kideys et al. 2000). Moreover, in a recent review, Mills (2001) showed that jellyfish populations were not only under change in the Black Sea, but were on the increase on a world scale. She claims that this process could have severe consequences for marine ecosystems and fishery yields world-wide, since many gelatinous zooplankters are both competitors and predators of young fish. This implies that it is important to extend our knowledge on cnidarians and ctenophores, as their role in marine pelagic food webs will probably increase rather than decrease in importance (see also CIESM 2001).

Ctenophores do not show the changes between pelagic and sedentary stages that are typical of many jellyfish. Nevertheless, most populations of $P$. pileus show distinct seasonal fluctuations with, in the southern North Sea, individuals generally found between April and August (Greve and Reiners 1988). In recent years there seems to have been a shift in population dynamics, from a single very high peak in densities in May-June (Greve 1971) to a more even distribution over the whole summer (W. Greve, unpublished data), the causes of which are unknown. The reasons behind the absence of Pleurobrachia from the pelagic zone in winter are twofold. On the one hand, population densities are much lower than during the growing season. On the other hand, the adult individuals that overwinter are found closer to the sediment and, hence, less obvious in plankton samples. Nevertheless, much is still unknown 
concerning the population dynamics of Pleurobrachia, and other authors have observed other overwintering strategies for different Pleurobrachia species and different localities (Milne and Corey 1986; Attrill and Thomas 1996). When the population builds up through intense reproduction in spring, the average size of the individuals decreases, to reach a minimum around August (Greve 1971), and main reproduction is early in the season. Even though Pleurobrachia individuals are often also found in deeper water layers during the period of maximum densities (but see Kopacz 1994), several authors have observed that one of the additional reasons why Pleurobrachia are rarely found in the water column in winter is that they are still closer to the sediment (Fraser 1970; van der Veer and Sadee 1984). The reasons for this behaviour in winter are unknown, possibly it is an energy-saving strategy when densities of pelagic prey items are so low that finding sufficient food in the water column is not possible, which could be the case in winter. Greve (1972) observed that especially in winter situations, when temperatures are low, Pleurobrachia individuals cease to move their combs of cilia, resulting in a decrease in locomotion activity and passive sinking to the bottom. Greve proposed that, apart from the energy-saving aspect, this might also increase the food uptake, as near-surface benthic layers are probably relatively rich in prey items.

Benthic predators such as Pagurus, Carcinus and Crangon are efficient predators on individuals of Pleurobrachia that venture into the vicinity of the sediment; in fact, Pagurus reacts to the presence of Pleurobrachia in the water column by changing its food-search behaviour (Greve 1972). Moreover, in experimental set-ups on community structures, Sullivan et al. (1991) observed that the presence of benthos severely depressed the densities of ctenophores. The potential danger of benthic predators for Pleurobrachia would be most severe at colder temperatures, which could mean that Pleurobrachia could be an important link between benthic and pelagic zones of the ecosystem (bentho-pelagic coupling). Hence, in this study we set out to investigate the following questions, to assess the level of bentho-pelagic coupling as a result of the depth distribution of Pleurobrachia. (1) Do ctenophores have a higher tendency to be closer to the sediment at lower temperatures, as a result of the decrease in locomotion activity? (2) Does this result in an increased probability of being preyed upon by benthic predators under lower temperatures?

\section{Materials and methods}

To answer the questions posed above, we carried out the following set of experiments: (1) the determination of the cilia beat rate of Pleurobrachia pileus individuals under different temperatures; (2) the assessment of the (resulting) depth distribution of individuals kept under different temperature regimes; (3) a reassessment of predation rates of benthic predators on $P$. pileus under early summer $\left(8^{\circ} \mathrm{C}\right)$ conditions; (4) an assessment of the predation rates under winter $\left(2^{\circ} \mathrm{C}\right)$ conditions; and (5) the evaluation of the depth distribution of $P$. pileus individuals exposed to predators and to medium previously inhabited by predators under winter conditions.

\section{Animals}

The $P$. pileus individuals used in this study were caught in the winter of 2001-2002, in the German Bight around Helgoland. In order to obtain enough animals for our experiments, we used a range of different nets, which were towed through the water column at very low speeds. Animals were collected from the nets directly, and transferred to the laboratory. Here, they were introduced into the "Planktonkreisel" (Greve 1968), in which a continuous exchange of water generates a current minimising contact with the vessel and with the water surface. They were kept at $8^{\circ} \mathrm{C}$ under continuous light, as Pleurobrachia does not react to differences in light conditions (Greve 1972). The animals were fed daily with Artemia nauplii, and kept under these conditions for several weeks, before they were used in experiments. In the experiments we used only adult individuals of $P$. pileus, with sizes of around $2-3 \mathrm{~cm}$.

For the experiments with benthic predators we used the following species, all of which were also caught in the German Bight and kept in the laboratory for several weeks: the green crab Carcinus maenas, the hermit crab Pagurus bernhardus, the edible crab Cancer pagurus and the brown shrimp Crangon crangon. The selection of these predators was based on the studies of Greve (1972), who showed that especially Carcinus and Pagurus can consume considerable amounts of Pleurobrachia. Prior to experiments, the predators were kept at $4{ }^{\circ} \mathrm{C}$ and fed weekly.

\section{Experiments}

For the assessment of the frequency of the movement of the cilia in the combs, five individuals were kept in a $10 \mathrm{l}$ aquarium at $-1^{\circ} \mathrm{C}$, $2^{\circ} \mathrm{C}, 4^{\circ} \mathrm{C}, 6^{\circ} \mathrm{C}, 8^{\circ} \mathrm{C}$ and $16^{\circ} \mathrm{C}$ for a week, to adjust the animals to the experimental temperatures. Subsequently, the animals were filmed using a black and white video camera (Panasonic WVBP213E, with remote access) and recorded using a Panasonic AG$4700 \mathrm{EY}$ video recorder. Every individual animal was recorded for a total period of $5 \mathrm{~min}$. The experiments were carried out under the same light conditions as the vertical distribution experiments. The tapes were analysed, and the average frequency of cilia movement over the $5 \mathrm{~min}$ recording time per animal was established.

The experiments on the vertical distribution of Pleurobrachia were carried out in Plexiglas cylinders, with a diameter of $19 \mathrm{~cm}$ and a height of $1 \mathrm{~m}$, yielding a volume of 281 . Ten individuals of $P$. pileus were introduced into these vessels, and at regular time intervals the distribution of these ten animals in the column was determined. Obviously, the measurements of the ten animals within one tube are not independent. Hence, we averaged the heights above the bottom for the ten animals, and used this average in our further analyses. Replication was obtained by using four cylinders per treatment. In order to investigate the influence of the temperature on the vertical distribution of the individuals we carried out these experiments at the following temperatures: $-1^{\circ} \mathrm{C}, 2^{\circ} \mathrm{C}, 4^{\circ} \mathrm{C}$, $6^{\circ} \mathrm{C}, 8^{\circ} \mathrm{C}$ and $16^{\circ} \mathrm{C}$. In all cases, four cylinders were each filled with ten animals from the Planktonkreisel, and these columns were then transferred from $8^{\circ} \mathrm{C}$ (stock culture temperatures) to the experimental temperatures. The change in temperature of the water took as long as $8 \mathrm{~h}$. During this period, we established the vertical distribution of the animals every $2 \mathrm{~h}$. For the next 7 days, the observation interval was $12 \mathrm{~h}$. Pleurobrachia were not fed during the experiments, to avoid confounding the effects of prey distributions on the distribution of the ctenophores (Esser, personal observation). Previous investigations had shown that the starvation resistance of Pleurobrachia is much longer than the 7 days our experiments lasted, ranging up to 3 months (Greve 1972). More- 
over, preliminary experiments comparing fed with non-fed animals did not show significant effects of feeding regime on changes in the animals' distributions over time. The distribution data were analysed using a repeated-measurement ANOVA, with temperature as a fixed factor, the average depth of ten animals in one cylinder as the dependent variable, and time as the repeated-measurement variable. Not only did we perform this analysis for the average depth in a cylinder, we also determined the variance in every cylinder using the same analysis: temperature and time as the independent variables and variance of the ten animals in one vessel as the dependent one. This was carried out to assess the level of homogeneity in the vessels: do animals all react in a similar way, or are there large changes over time?

Predation rates of Carcinus maenas, Pagurus bernhardus, Cancer pagurus and Crangon crangon on $P$. pileus were established in 5-1 beakers containing one predator and three prey individuals. In the experiments, we used adults of all species, except for C.pagurus, of which we used animals of around $10 \mathrm{~cm}$ in size. The size of the other predators ranged from $3.5 \mathrm{~cm}$ for $P$. bernhardus, to $6-7 \mathrm{~cm}$ for $C$. crangon and $C$. maenas. The duration of the experiments was 3 days. Every day we counted the number of remaining $P$. pileus and added animals to the experimental vessels from which animals had been eaten by the benthic predators. Every treatment was carried out in triplicate. This experiment was preformed at $2^{\circ} \mathrm{C}$ and $8^{\circ} \mathrm{C}$, under constant light conditions.

In order to investigate whether the vertical distribution of $P$. pileus was influenced by the presence of predators, we carried out an additional experiment with 28-1 columns, similar to the one described above. Animals were adapted to $2^{\circ} \mathrm{C}$ for 7 days and subsequently exposed to water that had previously been inhabited by benthic predators (a combination of three $C$. pagurus, three $P$. bernhardus, and five C. maenas in 101 of water for 10 days). Initially 31 of this predator water was added to the 28-1 cylinders, and, during the experiment, an additional 11 every day, to avoid loss of predator-kairomones as a result of bacterial action (Loose et al. 1993). The experiment ran for 7 days; animals were not fed during these experiments.

\section{Results}

In the experiment on the effect of temperature on the movement frequency of the cilia, we observed that animals that were attached to the water surface showed very low activity. They hardly moved their cilia irrespective of the temperature to which they were exposed. Hence, in our analysis, we omitted these animals and concentrated on those in the water column and those close to the bottom of the vessel. In these groups, the frequency of movement of the cilia in the combs of individual Pleurobrachia pileus was significantly affected by the temperature to which the animals were exposed (Fig. $1 ; F_{5,21}=2.71 ; P=0.04$ ), with animals kept at higher temperatures showing higher frequencies of movement of the cilia.

In the experiment on the effect of temperature on the vertical distribution of $P$. pileus we observed that, especially at the lower temperatures, the animals first preferred the near-surface levels of the cylinders, but, after 2-3 days, the average height of the animals in the cylinders started to decrease (Fig. 2). This pattern was not obvious for the higher temperatures. The analysis of variance showed that temperature did not significantly affect the vertical distribution of $P$. pileus $\left(F_{5,18}=2.74\right.$; $P=0.051)$, but that time $\left(F_{17,306}=5.53 ; P<<0.001\right)$ and the interaction between time and temperature did

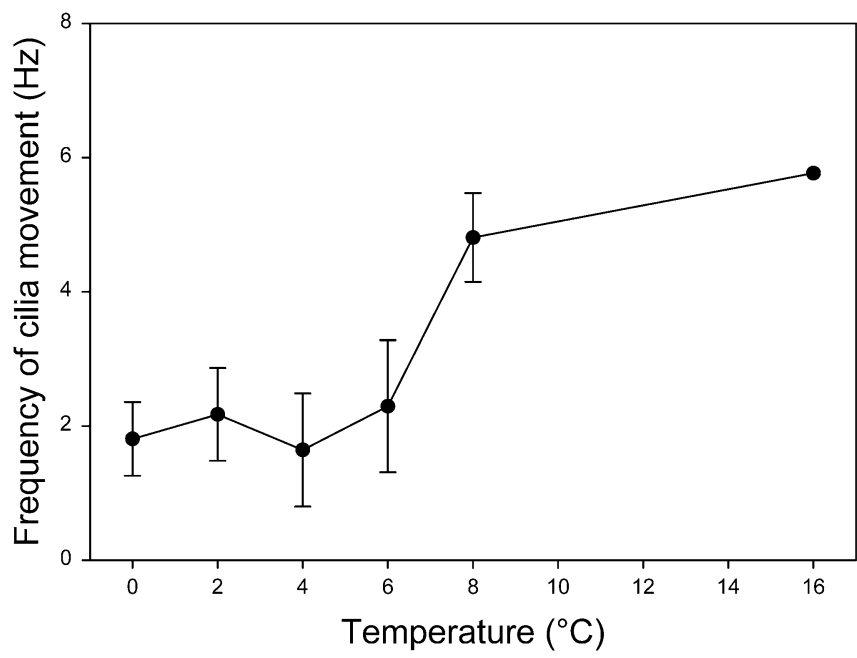

Fig. 1 Pleurobrachia pileus. Cilia movement frequency under different temperature regimes, ranging from $-1^{\circ} \mathrm{C}$ to $16^{\circ} \mathrm{C}$. Only animals in the water column and near the bottom were included (see "Results"). Error bars: standard errors $(n=5)$

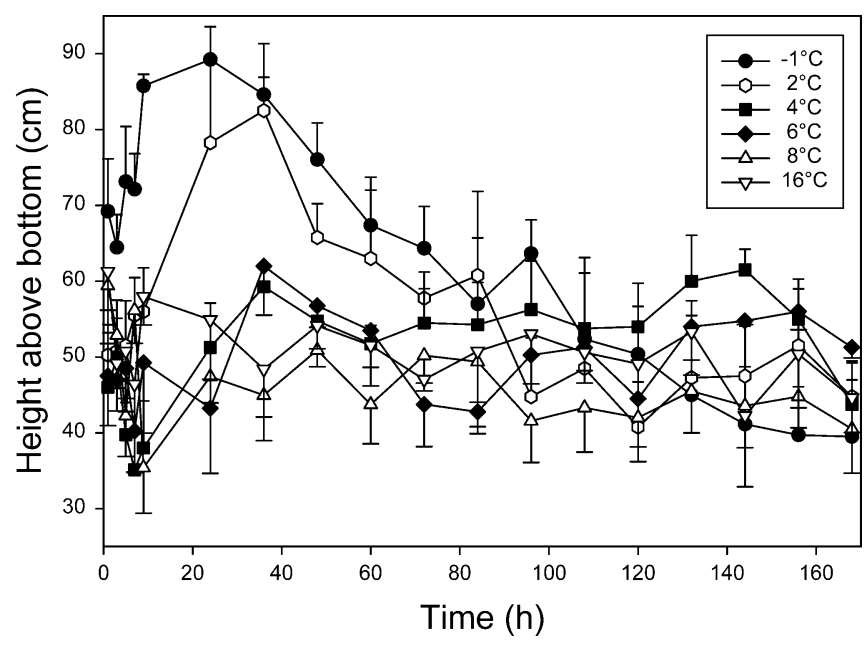

Fig. 2 Pleurobrachia pileus. Vertical distribution under different temperature regimes, ranging from $-1{ }^{\circ} \mathrm{C}$ to $16^{\circ} \mathrm{C}$. Error bars indicate standard errors $(n=4)$, for clarity reasons they are given in one direction only. Animals were transferred from the stock cultures $\left(8^{\circ} \mathrm{C}\right)$ to the experimental temperatures at time zero

$\left(F_{85,306}=2.97 ; P<<0.001\right)$. Omitting the first $24 \mathrm{~h}$ of the experiments, to exclude the adaptation effect, did not qualitatively change the results of the analyses: no significant temperature effect but a significant time and interaction effect. In the ANOVA of the variances within the tubes, we observed a significant effect of temperature only $\left(F_{5,18}=5.39 ; \quad P=0.003\right)$. Time $\left(F_{17,306}=0.85\right.$; $P=0.62)$ and the interaction between time and temperature $\left(F_{85,306}=0.89 ; \quad P=0.73\right)$ were not significant (Fig. 3). In fact, post hoc comparisons showed that the significant effect of temperature was caused only by the higher variances within tubes at the lowest temperature. All other temperatures showed similar variances within tubes over the whole experimental period. 




Fig. 3 Pleurobrachia pileus. Standard deviations within tubes under different temperature regimes, ranging from $-1^{\circ} \mathrm{C}$ to $16^{\circ} \mathrm{C}$. Error bars indicate standard errors $(n=4)$, for clarity reasons they are given in one direction only. Animals were transferred from the stock cultures $\left(8^{\circ} \mathrm{C}\right)$ to the experimental temperatures at time zero

Three out of four predators consumed significant numbers of $P$. pileus individuals in the experiment on predation rates under early summer conditions $\left(8^{\circ} \mathrm{C}\right)$, as shown in Fig. 4 (top panel). These values were probably a very strong underestimation of the possible predatory impact on Pleurobrachia populations, as we observed that even with higher densities of prey items (ten instead of three Pleurobrachia per vessel) most of the Pleurobrachia were eaten by Crangon crangon and Pagurus bernhardus. Nevertheless, this experiment showed that under these conditions predation rates of benthic predators on $P$. pileus can be substantial, provided the probability that the predator and prey actually meet is high (i.e. the vessel is small enough). In contrast (Fig. 4, bottom panel), almost no predation was observed on Pleurobrachia under winter conditions $\left(2^{\circ} \mathrm{C}\right)$. Only $P$. bernhardus was observed to consume some Pleurobrachia, but at much lower levels than at $8^{\circ} \mathrm{C}$. In fact, at these temperatures the predators showed very little activity, and did not even consume a fresh mussel, which was given to them after the experiment.

In a pre-experiment, in which we kept ten $P$. pileus in the presence of benthic predators in a 1801 column, to give the predators enough space, we observed that all of the Pleurobrachia individuals were near the surface of the water the whole time at $2^{\circ} \mathrm{C}$, and none showed the typical sinking after 2-3 days. This means that the Pleurobrachia individuals sense the presence of predators, and avoid the layers in which these predators occur. Since this result was very clear, we decided to immediately go one step further, and test for the effect of the presence of the predatorchemicals on the vertical distribution of the ctenophores. We observed that the presence of invertebrate benthic predators in the water, before this was used for our experiments on the vertical distribution of Pleurobrachia, significantly affected the average height of the individuals

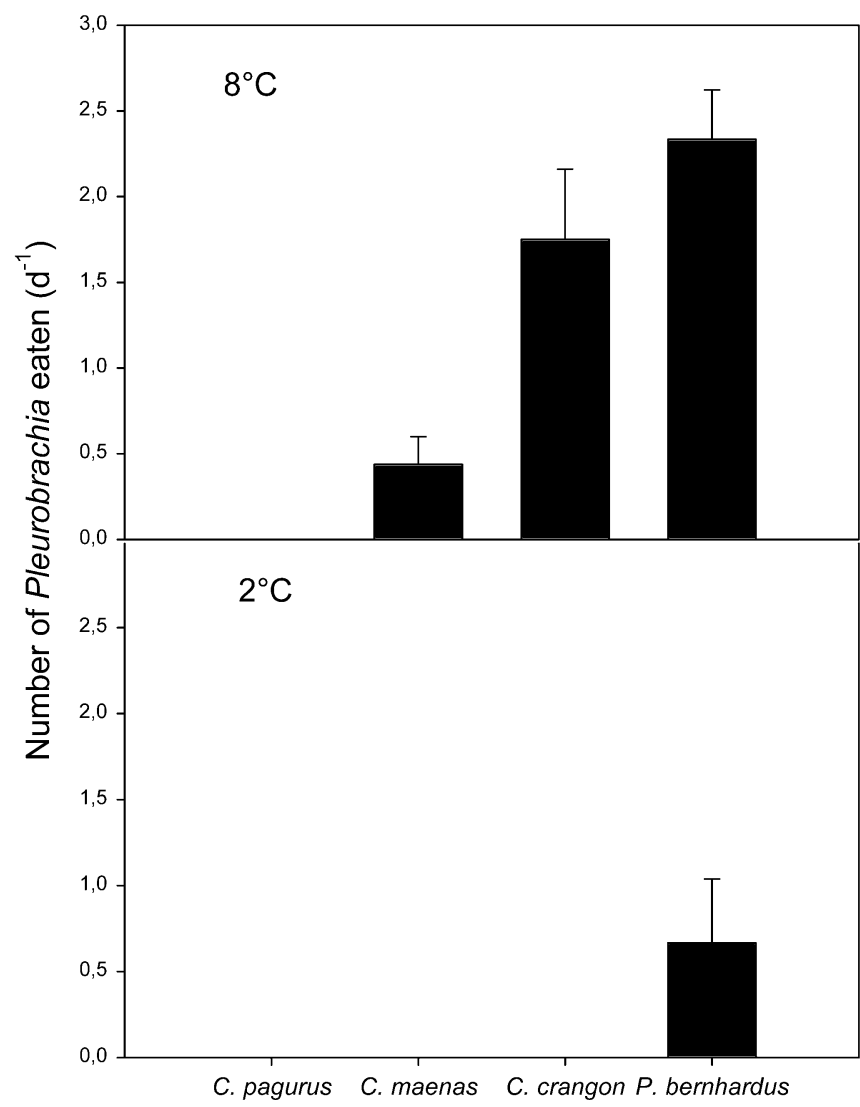

Fig. 4 Pleurobrachia pileus. Number of individuals eaten per day by four different benthic predators (Cancer pagurus, Carcinus maenas, Crangon crangon and Pagurus bernhardus) under early summer conditions $\left(8^{\circ} \mathrm{C}\right.$, top panel $)$ and winter conditions $\left(2^{\circ} \mathrm{C}\right.$, bottom panel). Error bars: standard errors

above the bottom of the vessel $\left(F_{1,4}=42.7 ; P=0.003\right)$, whereas the effect of time and the interaction between time and treatment were not significant $\left(F_{6,24}=0.54 ; P=0.78\right.$ and $F_{6,24}=2.4 ; P=0.06$, respectively). Whereas the average height above the bottom of the vessel was $28.7 \mathrm{~cm}$ (8.1 SE) under control conditions, the ctenophores were found predominantly at $77.2 \mathrm{~cm}(6.1 \mathrm{SE})$ when exposed to water previously inhabited by benthic predators (Fig. 5). Thus, individuals of Pleurobrachia avoided the dangerous zones in our vessels by staying closer to the water surface, even when only the so-called "predator water" was present.

\section{Discussion}

In this study we set out to investigate the importance of vertical migration behaviour of the ctenophore Pleurobrachia pileus for bentho-pelagic coupling processes. Greve $(1971,1972)$ observed that individuals of Pleurobrachia were normally found in deeper layers in winter, that benthic predators can eat substantial amounts of Pleurobrachia, and that Pleurobrachia sink to deeper layers, because they lower the frequency of cilia movement. From these observations the hypothesis that, 


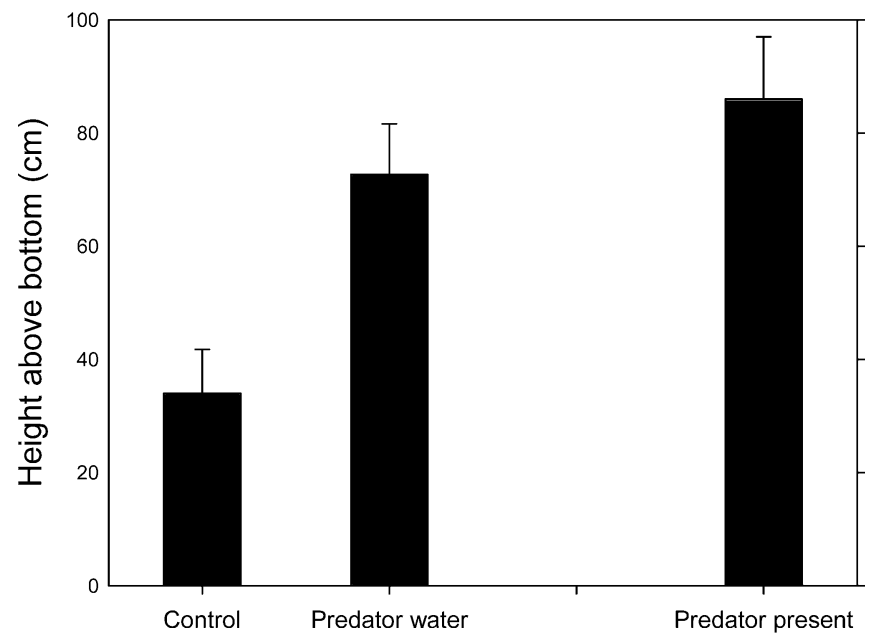

Fig. 5 Pleurobrachia pileus. Vertical distribution under predation regimes. Control and predator water treatments were carried out in one experiment (see "Results"), for comparison we have included the average height of the animals in the larger container (180 l) with the predators physically present. Error bars: standard errors

especially under lower temperatures, bentho-pelagic coupling should be strong is straightforward, and easy to test. In the present study, we show that the hypothesis most likely needs to be rejected, at least with respect to the benthic predators investigated here. Even though we observed a significant effect of temperature on the frequency of cilia movement, we could not link these changes in comb movement frequency to the predominant position in the water column. In fact, $P$. pileus showed the lowest activity when it was attached to the surface of the water. Moreover, we did not observe that animals can be found lower in the water column at lower temperatures. In the presence of predators, or of water previously inhabited by predators, Pleurobrachia avoided the layers lower in the water column, and even when severely restricted in smaller vessels the predators did not consume substantial amounts of Pleurobrachia under winter conditions, whereas they did under early summer conditions. All of this leads to the conclusion that under winter conditions, predation by benthic predators is most likely not an important source of mortality for Pleurobrachia.

Predation of $P$. pileus by benthic predators is not the only possible bentho-pelagic link Pleurobrachia could be involved in. Some reports exist that Pleurobrachia species consumed substantial amounts of larvae of benthic organisms (Greve 1972; Chen et al. 2003), although in other studies the main prey items were pelagic copepods (Frid et al. 1994; Mutlu and Bingel 1999), but, as combined estimates of daily rations (Bamstedt 1998), food selectivities and Pleurobrachia densities are very rare, it is not possible at this stage to estimate the impact of predation by Pleurobrachia on the population dynamics of benthic organisms.

This study shows that temperature as such does not have a significant influence on the depth distribution of $P$. pileus in our experiments. We only observed a strongly significant interaction between time and temperature, which was caused mainly by the reaction of the animals to very low temperatures. When exposed to water of $-1^{\circ} \mathrm{C}$ and $2^{\circ} \mathrm{C}$, the first reaction of the Pleurobrachia individuals was to move to the surface of our vessels, but after $36 \mathrm{~h}$ they gradually moved back to the average height of $40 \mathrm{~cm}$ above the bottom of the vessels. Most likely this was some sort of a shock reaction to the very low temperatures, but it could also be that this reflects some diel vertical migration behaviour, even though this is not very likely, since the animals had been kept in the laboratory under constant light conditions for longer periods already. Moreover, conflicting reports exist whether Pleurobrachia performs diel vertical migration at all [compare Mutlu and Bingel (1999) with Kideys and Romanova (2001) for the same system], and whether these patterns are induced by diel (Wang et al. 1995) or other (tidal) cycles (Kopacz 1994).

We conclude that the predominance of Pleurobrachia in layers near the sediment in winter is most likely not a result of the lower temperatures. Nevertheless, we observed slight differences in behaviour of the ctenophores under the different temperature regimes. Especially at the two lowest temperatures, quite a few animals were found lying on the bottom of the vessels, whereas at the higher temperatures most of them were still in the water column. In this context it is important to note that the average height of the animals in a column can be somewhat misleading at times. Five animals stuck to the surface and five animals lying on the bottom would yield the same result as ten animals at $50 \mathrm{~cm}$. The plot of the variances (Fig. 3) in the temperature experiment indicates that at times this subdivision of the population was indeed the case, most predominantly so at the lowest temperatures. Nevertheless, in these cases we observed that animals were not permanently in one position, but were actively moving through the water column. This shows that had we used longer columns we would have indeed found more animals in the water column, and as such the average of the distribution is indicative for the behaviour of the animals.

Even though temperature significantly affected the frequency with which Pleurobrachia individuals moved their cilia, this does not seem to affect the position of the animals in the water column, as was proposed by Greve (1972). Not only did we not find an effect of temperature on the distribution of the animals, we observed that the animals at the bottom showed the whole range of activity possible, and, hence, passive sinking of Pleurobrachia as a result of lower locomotion activity is highly unlikely. Of course, it is tempting to speculate on what determines the vertical position in the water column if it is not the cilia beat rate. Some reports exist that ctenophores regulate their vertical position by changing the concentrations of sulphate (Bidigare and Biggs 1980), although this conclusion has been questioned by Mills and Vogt (1984). It could also 
be the case that whether an animal has fed or not affects the buoyancy. In fact, we observed in another experiment that Pleurobrachia individuals, which were fed during the experiments were significantly lower in the water column than those that were unfed. It was, however, unclear, whether this was an effect of reduced buoyancy as a result of ingestion of particles or of search for the food items which were predominantly low in the water column.

Three of the four benthic predators that were used in this study were able to feed on $P$. pileus. Only Cancer pagurus did not catch any Pleurobrachia individuals. Potentially, this is an artefact of our experimental set-up; the experimental vessels might have been too small for $C$. pagurus to show its normal feeding behaviour, even though we used sub-adult animals, which were only slightly larger than the Carcinus individuals. Most likely, Pleurobrachia is outside the food spectrum of C. pagurus. Nevertheless, the other predators did consume substantial amounts of Pleurobrachia, but only under early summer $\left(8^{\circ} \mathrm{C}\right)$ conditions, and not when the temperature was lower (Fig. 4). Most likely, the number of Pleurobrachia consumed at $8^{\circ} \mathrm{C}$ in our experiments was a very strong underestimation of the potential impact benthic predators can have on Pleurobrachia, as in many cases the three individuals were eaten very quickly, and a higher number of Pleurobrachia individuals in the experimental vessels yielded much higher predation rates. We were, however, not interested in the estimation of exact values for potential predation rates, but wanted to establish whether the benthic predators consumed Pleurobrachia at all. This was the case at $8^{\circ} \mathrm{C}$, but not at $2^{\circ} \mathrm{C}$. As the predators originated from cultures in which they were relatively well fed, it could be the case that under the lower temperatures, they simply did not need much food to survive, and the duration of the experiment was too short. This is likely, as they did not even feed on a Mytilus that was given to them opened. Most likely, activity at these temperatures was so low, that they did not feed at all.

The presence of benthic predators significantly affected the vertical distribution of Pleurobrachia. Not only when they were present, but also when the ctenophores were kept in water that had previously been inhabited by benthic predators: they were significantly higher in the water column than in the controls. The main predator of P. pileus in the water column is Beroe gracilis, another ctenophore. Greve (1971) has shown that the influence of this predator dominates the population dynamics of Pleurobracia, especially in summer. Interestingly, even though a benthic predator such as Pagurus is known to react to the presence of Pleurobrachia by increasing its food-search behaviour (Greve 1972), next to nothing is known about the link between Beroe and Pleurobrachia. Most likely, the behaviour of Pleurobrachia would change with Beroe present in the water column, and the appropriate reaction of the animals would seem to leave the pelagic zone. Most likely, the resulting behaviour will depend on the strength of the different information signals, and hence individuals should assess the predation risks in the different zones and change their vertical distribution to minimise predation risk.

Although chemicals are widely recognised as having critical importance ecologically, the mechanisms by which such stimuli contribute to processes that structure communities are largely unexplored (see for a reviews Atema 1995; Tollrian and Harvell 1999; Zimmer and Butman 2000). Nevertheless, investigations on phenomena in chemical ecology of marine organisms are increasing, and information is now available that sensory perception of chemical signals influences predation (e.g. Hay and Fenical 1988; Zimmer-Faust 1989), courtship and mating (e.g. Hardege and Bentley 1984), aggregation and school formation (e.g. Ratchford and Eggleston 2000), and habitat selection (e.g. Pawlik 1990). Most published examples on chemical communication processes in marine environments have focussed on the benthos (e.g. Harvell 1998), and the number of studies in pelagic systems is still relatively low (but see Ohman et al. 1983; Forward and Rittschof 2000). The role of predator-induced changes in prey organisms caused by chemical substances (kairomones) has received very little attention even in benthos, but it is highly unlikely that organisms do not react to the presence of predators, as this will result in higher probabilities of being consumed. This paper presents one of the first examples of chemical communication processes between the benthos and the pelagic zone, but at this point we can only speculate on the nature of the substances that are produced by the benthic crustaceans and detected by Pleurobrachia. Forward and Rittschof (2000) showed that in the reaction of crab larvae (Rhithropanopeus harrisii) to the presence of fish polysaccharides played a role, whereas the spiny lobster Panulirus argus used mixtures of different substances to discriminate between different predators (Fine-Levy et al. 1989). In many other well-known examples of chemical communication the chemical structure of the substances involved remains unclear (Lass and Spaak 2003).

In conclusion, we have shown that benthic predators can consume considerable amounts of Pleurobrachia when these Pleurobrachia are close enough to the predators to be caught. We have also shown that the hypothesis that especially in winter, when Pleurobrachia is thought to be closer to the sediment and as such more vulnerable to benthic predators, these predators did not feed on Pleurobrachia. The effect of temperature was visible in the movement frequency of the cilia in Pleurobrachia, but this could not be linked causally to the vertical distribution of the ctenophores. Moreover, Pleurobrachia avoid the water layers close to the sediment when crustacean predators are present. Hence, Pleurobrachia probably does not represent a very strong link in bentho-pelagic coupling processes through predation by crustaceans. 
Acknowledgements We thank the crews of the "Aade" and "Uthörn" for their help in collecting samples, and O. Goemann, who made the benthic predators available. F. Buchholz, L. Gutow, G. Graf and K. Wiltshire are thanked for their constructive criticism on earlier versions of this manuscript. The experiments comply with the current laws of the country in which the experiments were performed.

\section{References}

Atema J (1995) Chemical signals in the marine environment-dispersal, detection, and temporal signal analysis. Proc Natl Acad Sci USA 92:62-66

Attrill MJ, Thomas RM (1996) Long-term distribution patterns of mobile estuarine invertebrates (Ctenophora, Cnidaria, Crustacea: Decapoda) in relation to hydrological parameters. Mar Ecol Prog Ser 143:25-36

Bamstedt U (1998) Trophodynamics of Pleurobrachia pileus (Ctenophora, Cydippida) and ctenophore summer occurrence off the Norwegian north-west coast. Sarsia 83:169-181

Bidigare RR, Biggs DC (1980) The role of sulfate exclusion in buoyancy maintenance by siphonophores and other oceanic gelatinous zooplankton. Comp Biochem Physiol A 66:467-472

Chen LH, Chen G, Li SJ, Guo DH (2003) Studies on feeding of ctenophore Pleurobrachia globosa in Xiamen Harbour. J Xiamen Univ Nat Sci 42:228-232

CIESM (Commission Internationale pour l'Exploration Scientifique de la Mer Méditerranée) (2001) Gelatinous zooplankton outbreaks: theory and practice. Workshop series vol 14, CIESM, Monaco, pp 1-112

Fine-Levy JB, Daniel PC, Girardot MN, Derby CD (1989) Behavioral resolution of quality of odorant mixtures by spiny lobster differential aversive conditioning of olfactory responses. Chem Senses 14:503-524

Forward RB, Rittschof D (2000) Alteration of photoresponses involved in diel vertical migration of a crab larva by fish mucus and degradation products of mucopolysaccharides. J Exp Mar Biol Ecol 245:277-292

Fraser JH (1970) The ecology of ctenophore Pleurobrachia pileus in Scottish waters. J Cons Int Explor Mer 33:149-168

Frid CLJ, Newton LC, Williams JA (1994) The feeding rates of Pleurobrachia (Ctenophora) and Sagitta (Chaetognatha), with notes on the potential seasonal role of planktonic predators in the dynamics of North Sea zooplankton communities. Neth J Aquat Ecol 28:181-191

Greve W (1968) The 'Planktonkreisel', a new device for culturing zooplankton. Mar Biol 1:201-203

Greve W (1971) Ecological investigations on Pleurobrachia pileus. 1. Field studies. Helgol Wiss Meeresunters 22:303-325

Greve W (1972) Ecological investigations on Pleurobrachia pileus. 2. Laboratory investigations. Helgol Wiss Meeresunters 23:141164

Greve W, Reiners F (1988) Plankton time-space dynamics in German Bight North Sea: a systems approach. Oecologia 77:487-496

Hardege JD, Bentley MG (1984) Spawning synchrony in Arenicola marina: evidence for sex pheromonal control. Proc R Soc Lond B Biol Sci 264:1041-1047

Harvell CD (1998) Genetic variation and polymorphism in the inducible spines of a marine bryozoan. Evolution 52:80-86
Hay ME, Fenical W (1988) Marine plant-herbivore interactions: the ecology of chemical defense. Annu Rev Ecol Syst 19:111145

Kideys AE, Romanova Z (2001) Distribution of gelatinous macrozooplankton in the southern Black Sea during 1996-1999. Mar Biol 139:535-547

Kideys AE, Kovalev AV, Shulman G, Gordina A, Bingel F (2000) A review of zooplankton investigations of the Black Sea over the last decade. J Mar Syst 24:355-371

Kopacz U (1994) Evidence for tidally-induced vertical migration of some gelatinous zooplankton in the Wadden Sea area near Sylt. Helgol Meeresunters 48:333-342

Kuipers BR, Gaedke U, Enserink L, Witte H (1990) Effect of ctenophore predation on mesozooplankton during a spring outburst of Pleurobrachia pileus. Neth J Sea Res 26:111-124

Lass S, Spaak P (2003) Chemically induced anti-predator defences in plankton: a review. Hydrobiologia 491:221-239

Loose CJ, von Elert E, Dawidowicz P (1993) Chemically-induced diel vertical migration in Daphnia: a new bioassay for kairomones exuded by fish. Arch Hydrobiol 126:329-337

Mills CE (2001) Jellyfish blooms: are populations increasing globally in response to changing ocean conditions? Hydrobiologia 451:55-86

Mills CE, Vogt RG (1984) Evidence that ion regulation in hydromedusae and ctenophores does not facilitate vertical migration. Biol Bull (Woods Hole) 166:216-227

Milne WR, Corey S (1986) Distributional patterns of the ctenophores Pleurobrachia pileus and Beroe cucumis in the Bay of Fundy region Canada. Can J Zool 64:2639-2644

Mutlu E, Bingel F (1999) Distribution and abundance of ctenophores, and their zooplankton food in the Black Sea. I. Pleurobrachia pileus. Mar Biol 135:589-601

Ohman MD, Frost BW, Cohen EB (1983) Reverse diel vertical migration: an escape from invertebrate predators. Science 220:1404-1407

Pawlik JR (1990) Natural and artificial induction of metamorphosis of Phragmatopoma lapidosa californica Polychaeta Sabellariidae with a critical look at the effects of bioactive compounds on marine invertebrate larvae. Bull Mar Sci 46:512536

Ratchford SG, Eggleston DB (2000) Temporal shift in the presence of a chemical cue contributes to a diel shift in sociality. Anim Behav 59:793-799

Sullivan BK, Doering PH, Oviatt CA, Keller AA, Frithsen JB (1991) Interactions with the benthos alter pelagic food web structure in coastal waters. Can J Fish Aquat Sci 48:2276-2284

Tollrian R, Harvell CD (1999) The evolution of inducible defenses. Princeton University Press, Princeton

van der Veer HW, Sadee CFM (1984) Seasonal occurrence of the ctenophore Pleurobrachia pileus in the western Dutch Wadden Sea. Mar Biol 79:219-228

Wang Z, Thiebaut E, Dauvin JC (1995) Spring abundance and distribution of the ctenophore Pleurobrachia pileus in the Seine estuary: advective transport and diel vertical migration. Mar Biol 124:313-324

Zimmer RK, Butman CA (2000) Chemical signaling processes in the marine environment. Biol Bull (Woods Hole) 198:168-187

Zimmer-Faust RK (1989) The relationship between chemoreception and foraging behavior in crustaceans. Limnol Oceanogr 34:1367-1374 